\title{
Vocabulary Size of University of Aden English Language Students
}

\author{
Abdulnaser Mohammed Ali Naqeeb \\ University of Aden, Aden, Yemen \\ naser77sam@yahoo.co.uk
}

\section{ARTICLE HISTORY \\ Received : 2020-09-21 \\ Revised : 2020-09-23 \\ Accepted : 2021-04-21}

\section{KEYWORDS}

Vocabulary Size

Nation Vocabulary size test (VST)

Range

Word Family

\begin{abstract}
This research paper tried to evaluate English students' vocabulary size by using Nation Vocabulary size tests (VST). The study used a sample of the third level students at the English-Faculty department of Education-Aden at the University of Aden in three categories according to their academic achievement in the class $($ High $=80-100$, Medium $=70-79.99$ and Low $=$ less than 69.99 $)$. The researcher used Nation and Beglar (2007) (14000) vocabulary size test to measure the vocabulary size. Based on the analysis of students' correct answers in the VST, the study found that students' vocabulary size ranges between 1000-8000 words with variant percentages. It was found that $(80 \%)$ of third level students' vocabulary size (high 08-100 and medium 70-79.99) is in the range (1000$3000)$, (76\%) of third level students' vocabulary size (high 08-100) is in the range (1000-5000) and (51\%) are in the range (1000-8000). The study found that (59\%) of third level students (medium 70-79.99) are in the range (1000$5000)$ and $(40 \%)$ of them are in the range (1000-8000). The third level students (low, less than 69.99) recorded the lowest size by $(50 \%)$ in the range (1000$3000),(41 \%)$ in the range (1000-5000) and only (21\%) are in the range (10008000). Considering the total word size of the three categories together, the study found that (70\%) are in the range (1000-3000), (59\%) range in the range (1000$5000)$, and (37\%) are in the range (1000-8000).
\end{abstract}

\section{Introduction}

Vocabulary forms an essential element of a language. Instead, it can be said that words are the beginnings and origins of any human language. Languages were created from words and their associated meanings then grammar came to organise these words. Language acquisition, and similarly language learning, start by acquiring and learning words rather than other language elements. No words mean no language. Wilkins (1972) wrote that "[...] while without grammar very little can be conveyed, without vocabulary nothing can be conveyed" (111112).

Similarly, Lewis (1993, p. 89) stressed that "lexis is the core or heart of language." This statement shows the great value of words in any language. Moreover, Grabe (1991) and Frederiksen (1982) referred that second and foreign language researchers stress the great value of vocabulary knowledge in language competence.

Studies of learners' vocabulary size are very useful in diagnosing students' levels, commonly known as placement tests. Knowing learners' vocabulary size helps educators classify learners in their appropriate study levels in any educational program (Laufer \&
Nation, 1999). Schmitt (1994) referred that the vocabulary size test puts the learners in their suitable levels in any educational program. It will help those in charge of education programs in planning and designing admission and placement (entrance examinations). Schmitt (1994) said that vocabulary size tests help teachers know the deficiencies of their learners' vocabulary size and try to find solutions.

There are standard tools designed by experts to be used to measure the number of words a learner knows in a particular language which is usually called vocabulary size tests (VST) — knowing vocabulary size shows teachers, learners and even course and curricula designers where to start and teach. Vocabulary size test work as a diagnostic tool in this regard. Foreign and second language research stressed the importance of estimating learners' vocabulary size. Thus, studying learners' vocabulary size has become essential in any country or English as a foreign language (EFL) institution. There are many VSTs in ESL or English literature as a foreign language (EFL) or even first language learning. X-Lex developed by Milton and Meara, the Vocabulary Size Test developed by Nation and the Vocabulary Levels Test $(V L T)$, are examples of VSTs. This study will use Nation Vocabulary Size Test 2007 to estimate English 
Language students' vocabulary size. This test created by Nation \& Beglar (2007) identified the vocabulary size based on three categories, namely High (80-100), Medium (70-79.99), and Low (less than 69.99).

The tested students, in this case, will be the third level students in the University of Aden in Yemen because in this university and maybe in Yemen, no research has been done in this regard as far the researcher knows. Therefore, this study will contribute to Yemen's English language learning by estimating English language students' vocabulary size at the University of Aden. Moreover, this study might serve as diagnostic means of University of Aden English students' vocabulary size that will help in many aspects such as placement tests, designing course books and determining teaching materials needed for learners in different learning stages $(\mathrm{Hu} \&$ Nation 2000). Additionally, this study will help students know where they are in terms of vocabulary size, modify and develop their learning strategies, and improve their levels.

Therefore, this research paper proposes three major questions; (1) What is the vocabulary size of third level English language students in the University of Aden based on the three categories of Nation \& Beglar's (2017) Vocabulary Size Test (VST)? (2) What is the difference in vocabulary size among the categories of high, medium and low among the third level English language students?, and (3) What is the score of students at each vocabulary frequency level (i.e. 1000, 2000, 3000, 4000 5000, 6000, 7000 and 8000) based on the VST 2007?

\section{Literature Review}

This part will review the literature related to the topic of the study. This will include vocabulary size, vocabulary size test and previous studies relevant to the study's topic.

\subsection{Vocabulary Size}

Vocabulary size can be defined as the overall stock of words and their associated meanings and use a learner or speaker of a language knows. All learners or speakers of a language possess certain words that form an essential part of their proficiency or linguistic competence. Vocabulary size is sometimes referred to as breadth of vocabulary in comparison to the depth of vocabulary. Anderson and Freebody (1981, p.92) defined vocabulary size as "the number of words for which the person knows at least some of the significant aspects of meaning." Research is SLL and FLL showed that vocabulary size is significant in language proficiency. For example, Meara (1996) stressed this by saying:

"All other things being equal, learners with large vocabularies are more proficient in a wide range of language skills than learners with smaller vocabularies, and there is some evidence to support the view that vocabulary skills make a significant contribution to almost all aspects of L2 proficiency." (p.37).

Meara (1996) went further by referring that vocabulary size is a determining factor in second language learning and considered it "at the heart of communicative competence" (p.35). Some studies showed that vocabulary size is strongly correlated to reading competence (Ouellette 2006; Snow, Tabor, Nicholson, Kurland 1995) and, other studies showed relevance to success in school (Biemiller \& Boote 2006; Bornstein \& Haynes 1998). Other studies showed that vocabulary size is very relevant to using English in different situations. Schonell, Meddleton, and Shaw, 1956 referred that the knowledge of the most frequent 2000-word families in English forms the basic lexical stock needed for everyday oral communication. Hazenburg and Hulstijin (1996) contended that 10,000 words are enough for second language learners in the university. However, Eyckmans (2004) referred that "[w]hen learners' move on to read authentic texts in the target language, the consensus among applied linguists seems to be that 3,000 to 5,000-word families should suffice."

Regarding vocabulary size, research in a second or foreign language is in constant development and tries to figure out the number of words an EFL, ESL or native language speakers have. Schmitt (2000, p.2-3) referred that the English language has between 600,000 to over two million words and over 54000word families. (Nation (2006, p.59) referred that the English language has 88,000- 114,000-word families. Schmitt (2000) found that English native-speaking university students would have a vocabulary size of about 20,000-word families. Adolphs and Schmitt (2003) pointed out that second language learners need 2000-3000 of the most frequent words to communicate daily. Schmitt (2007) added that that second language learners need 5000 words to read authentic text. Dissimilarly, Hazenberg and Hulstijn (1996) pointed out that second language learners need around 10,000 words for starting academic study in the university.

Sciarone (1979), Laufer (1992), Nieuwborg (1992), and Nation (1993) claimed that the most frequent 5000 words cover around $90 \%-95 \%$ of word tokens in an average text for second language learners. It means that SLL or English as a foreign language (EFL) need 5000-8000-word families in the university study. Similarly, Nation (2010: 15) pointed out that "counting the 2,000 most frequent English words as the high-frequency words is still the best decision for learners going on to academic study" since these words cover about $80 \%$ of any text. 
In vocabulary size research, scholars differentiate between receptive vocabulary knowledge and productive vocabulary knowledge of a word. The first one refers to words that learners or users of a language store in their minds primarily read and listen to. Whereas the latter refers to the active words that are used in producing language in speaking or writing. This difference is the difference between using a word to understand and using a word to produce or express oneself.
Nation (2001, pp. 26-28) specified word knowledge in three elements (form, meaning and use). Knowing form means knowing its different parts, spelling and sounds, whereas knowing meaning refers to recognising its associated meanings and other words that connect to it. Simultaneously, knowledge of form means using its grammatical functions, collocations, and different parts of speech. He further classified word knowledge in the following table:

Table 2.1 Word Knowledge

\begin{tabular}{|c|c|c|c|}
\hline \multirow{3}{*}{$\frac{1}{2}$} & $\begin{array}{l}\frac{n}{0} \\
\frac{0}{9} \\
9\end{array}$ & $\mathrm{R}$ & $\begin{array}{l}\text { What does the word sound } \\
\text { like? } \\
\text { How is the word pronounced? }\end{array}$ \\
\hline & $\underset{\Xi}{\stackrel{\Xi}{\rightleftarrows}}$ & $\mathrm{R}$ & $\begin{array}{l}\text { What does the word look like? } \\
\text { How is the word written and } \\
\text { spelt? }\end{array}$ \\
\hline & 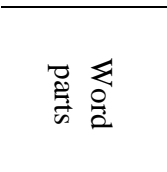 & $\mathrm{R}$ & $\begin{array}{l}\text { What parts are recognisable in } \\
\text { this word? } \\
\text { What words are parts needed } \\
\text { to express meaning? }\end{array}$ \\
\hline \multirow{3}{*}{ 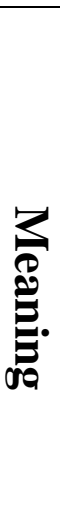 } & 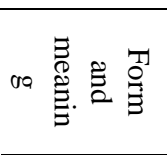 & $\mathrm{R}$ & $\begin{array}{l}\text { What meaning does this word } \\
\text { form signal? } \\
\text { What word form can be used } \\
\text { to express this meaning? }\end{array}$ \\
\hline & 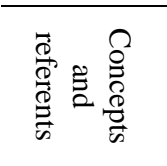 & $\nabla$ & $\begin{array}{l}\text { What is included in the } \\
\text { concept? } \\
\text { What items can the concept } \\
\text { refer to? }\end{array}$ \\
\hline & 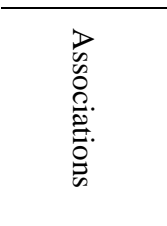 & $\nabla$ & $\begin{array}{l}\text { What others words does this } \\
\text { word make us think of? } \\
\text { What other words could we } \\
\text { use instead of this one? }\end{array}$ \\
\hline \multirow{3}{*}{$\underset{\mathscr{D}}{\mathscr{D}}$} & 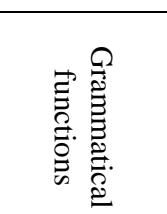 & $\mathrm{R}$ & $\begin{array}{l}\text { In what patterns does the word } \\
\text { occur? } \\
\text { In what patterns must we use } \\
\text { this word? }\end{array}$ \\
\hline & 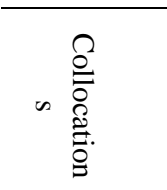 & $\mathrm{R}$ & $\begin{array}{l}\text { What words or types of the } \\
\text { word occur with this one? } \\
\text { What words or types of words } \\
\text { must we use with this one? }\end{array}$ \\
\hline & 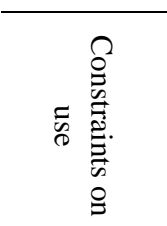 & $\mathrm{R}$ & $\begin{array}{l}\text { Where, when and how often } \\
\text { would we meet this word? } \\
\text { Where, when and how often } \\
\text { can we use this word? }\end{array}$ \\
\hline
\end{tabular}




\subsection{Vocabulary Size Test}

The vocabulary size test, abbreviated as VST, is a standard measurement tool designed to estimate the total number a speaker or a learner of a language knows. Generally, VSTs are used to measure native speakers' vocabulary size or second/foreign language learners' vocabulary size, or some are used to measure both native and foreign language learners. Nation and Beglar (2007) pointed out that VST is designed as "a proficiency measure used to determine how much vocabulary learners know" (p.10). VSTs are designed as monolingual, and some are designed as bilingual tests. Monolingual VSTs are designed as a multiplechoice test or yes/no questions in one language, while bilinguals are also designed as multiple or yes/no questions in two languages. In this type, the word is presented in English, and the answer or choices are presented in the learner's first language.

Generally, these tests can be found in print format or online versions. Based on design criteria, VSTs are of two main types. The first one is a dictionary-based test, and the second one is a corpus-based test. In the first one, the test taker selects a word family from each $\mathrm{N}$ pages (for example, from every 10th page and so on) from a dictionary that is expected to be known by the test taker. In the second one, the test taker has to select a word family from a corpus-based list. The list is ranked according to the most frequency (the first most frequent 1000 words, the second most frequent words). Nation (1990) referred that the second type is generally used with non-native speakers of English. Nation and Beglar (2007, p.1) confirmed that "[t]he Vocabulary Size Test is designed to measure both first language and second language learners' written receptive vocabulary size in English. Researchers all over the world use vocabulary size test.

Considering the validity and reliability of the VST, it is considered very valid and reliable by researchers. Beglar and Nation (2007, p. 9) reported that the vocabulary size test is "a reliable, accurate, and comprehensive measure of a learner's vocabulary size from the 1st 1,000 to the 14th 1,000-word families in English". Similarly, Beglar (2010) conducted a Rasch-based validation study of the monolingual VST among one-hundred-seventy Japanese and nineteen native English speakers. He found that the VST is very valid and reliable for measuring learners' vocabulary stock. The study indicated that the great majority of the test items showed an excellent fit to the Rasch model, high practicality in scoring and distribution, high reliability indices $(>0.96)$ and very low ambiguity. Other studies that proved the validity and reliability of the VST are Gyllstad 2012, Gyllstad, Vilkaite, and Schmitt 2015. The VSTs are free and available online from Paul Nation's website.

\subsection{Previous Studies}

Many studies have been found in the literature for English second or foreign language learners' vocabulary size. One study is Sungprakul (2016). This study investigated the vocabulary size of Thai university students. 40 EFL learners from the first, second, third, and fourth levels in the English department at Silpakorn University in Thailand participated in the study. The study found that the first-year students' vocabulary size ranges between 5800-5900 words from the first 10000 most frequent words, 6610.00 in the second level, 7100.00 in the third level, and 7360.00 fourth level. This study is considered weak because of the small size of the sample. Another study is Almasry (2012) in the UAE. He examined the relationship between breadth and depth of vocabulary knowledge and reading comprehension in an English as a foreign language (EFL) context. The sample of the study is ninety-three high school students. The study found a positive correlation between vocabulary knowledge and reading comprehension. Similarly, Almasry (2012) sample is small. Another study is also found in Iraq. The study is by Alfatle (2016). He examined the growth of vocabulary size and depth of word knowledge in Iraqi foreign language learners of English (EFLs) over four years of university instruction. The sample is forty students from each level (120). The study found that the growth of vocabulary increases by 800 to 1000 words annually.

\section{Method}

This study's research design is a descriptive one that uses the Nation and Beglar (2007) vocabulary size test. The data collected in this study is primarily quantitative.

\subsection{Participants}

The participants in this study are thirty students from the department of English at the Faculty of Education-Aden. They are male and female students. Their age ranges between 17 to 25 , and they come from rural and urban areas. According to their previous educational achievements, the students were categorised into three main groups (High $=80-100$, Medium $=70-79.99$ and Low $=$ less than 69.99). These groups are high, medium and low. Ten (10) students were selected from each group $=30$ students. It makes the sample as is in the following table:

Table 3.1 The Sample of the Study

\begin{tabular}{|c|c|c|c|c|}
\hline Level & 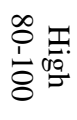 & 尚 & 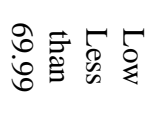 & Total \\
\hline $\begin{array}{l}\text { Third } \\
\text { Level }\end{array}$ & 10 & 10 & 10 & 30 \\
\hline
\end{tabular}




\subsection{Data Collection}

This study's data was collected by the Vocabulary Size Test developed by Paul Nation and Beglar (2007). It is the 14000 version that has 140 multiplechoice items. The test consists of 140 items distributed on fourteen sections representing the fourteen thousand most frequent words. The sections are arranged according to the frequency of the words starting with the first 1000 most frequent words and so on, until the 14th 1000 . The test is based on Nation's own British National Corpus BNC word family lists (Nation, 2006). Many studies check the validity and reliability of this test all over the world. This study is limited to measuring receptive vocabulary size of English language students at the University of Aden (third level students at the department of English/ Faculty of Education/Aden) using Nation and Beglar (2007) vocabulary size test one in the academic year 2018/2019.

\section{Findings}

After collecting the questionnaires, they were checked for completeness and labelled according to High, Medium and Low. Next, they were compared with the answer key to see the correct answers. Some questions handed unanswered. These were counted as zero-scores, although it was difficult to ascertain whether "no answer" was due to a genuine lack of knowledge of a word or the lack of time available or desire to complete the test. Correct answers were calculated in the three categories (High, Medium and Low). Microsoft Excel Sheet was used to get the mean score and percentages of students' correct answers in the three categories. Then the mean score of categories was calculated. The mean score and percentages of the first 3000, 4000 and 5000 words were calculated separately to know the percentages and means in these three levels. Then the mean score of these means was also taken to get the final result regarding the mean score of the first 5000 words. The tables 4.1 show the analysis, interpretation and discussion of the results:

Table 4.1 Third Level Students High 80-100

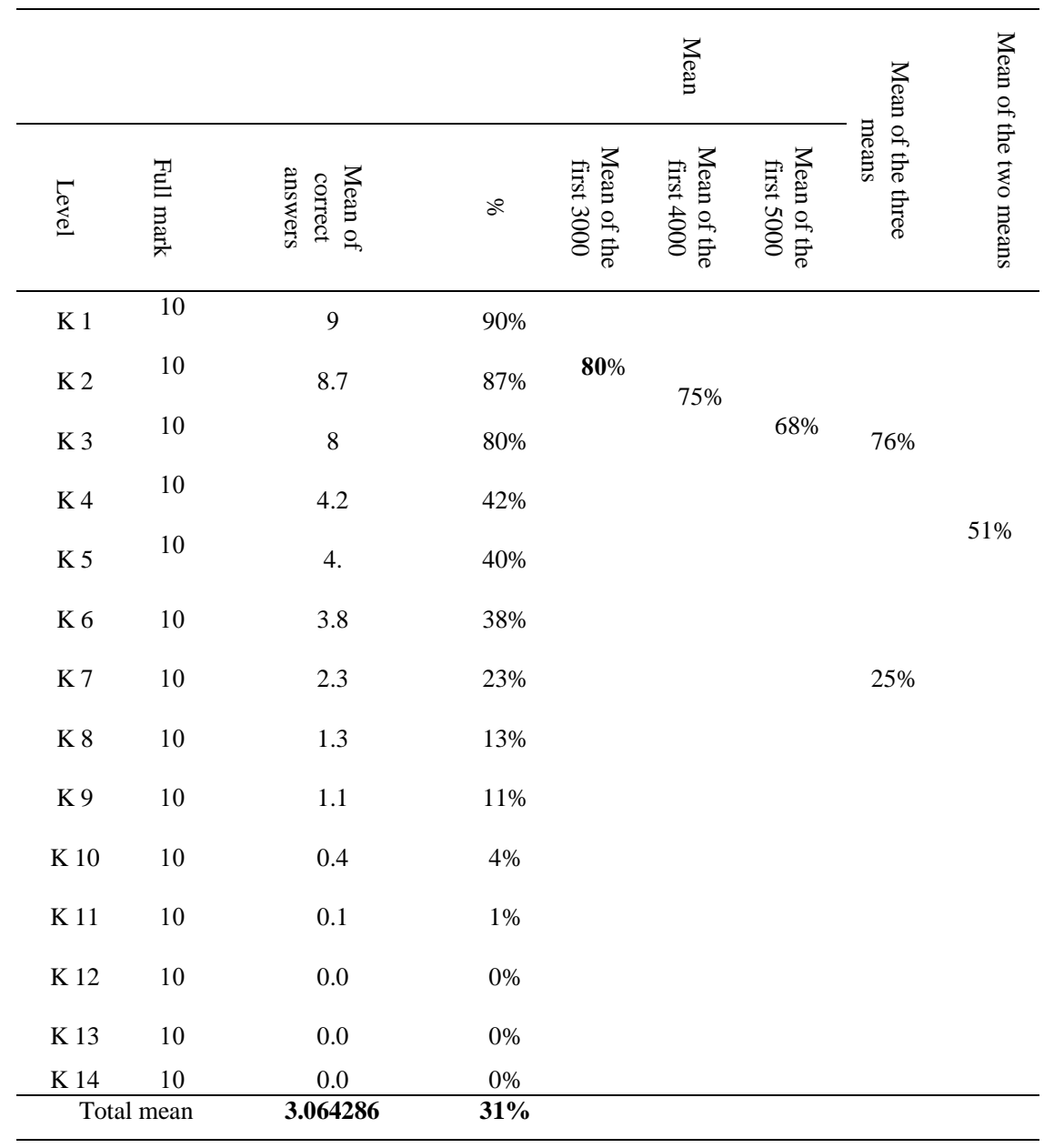




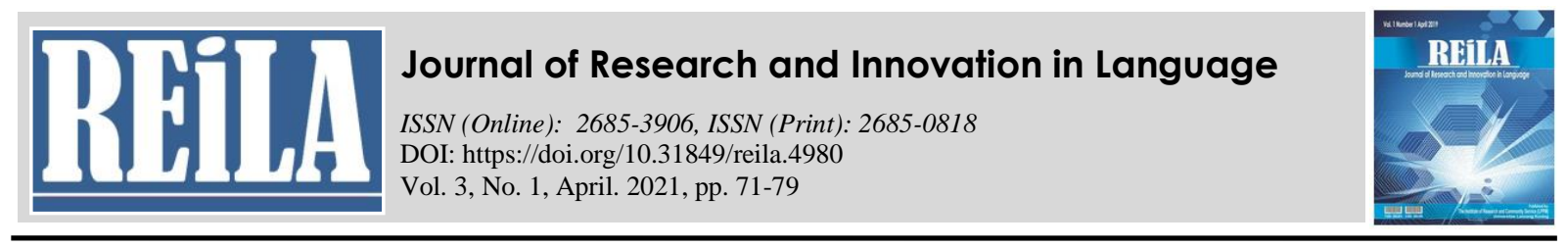

As can be seen from the table 4.1 and 4.2 , the mean score of students' correct answers (High 80-100) ranges from $\mathrm{K} 1$ to k11, but with variant mean scores, the highest is in $\mathrm{K} 1$ is $90 \%$, then the percentage decreases reaching only $1 \%$ in k11. Students' average scores in the levels k 8-k 22 are less than $20 \%$ which means that she is the only student who has vocabularies. Students with $80 \%$ and above are on the levels $\mathrm{k} 1$ to $\mathrm{k} 3$ with a mean score of $80 \%$. Beyond the 5,000-word level, the numbers decline further and further at each level until they reach the (1\%) in k 11 (11000). The mean score decreases in going to the $\mathrm{k} 4$, recording $75 \%$, and decreasing by going to the level $\mathrm{k}$ 5 to $\mathrm{k} 8$, recording $68 \%, 76 \%$, and $25 \%$, respectively. It means that students (Third Level Students High 80100) range of vocabulary size ranges between $\mathrm{k} 1$ with $80 \%$ to $\mathrm{k} 5$ with $76 \%$. This result is dissimilar to Sungprakul (2016), who studied Thai university students. 40 EFL learners from the first, second, third, and fourth levels in the English department at Silpakorn University in Thailand participated in the study. The study found that the first-year students' vocabulary size ranges between 5800-5900 words from the first 10000 most frequent words, 6610.00 in the second level, 7100.00 in the third level, and 7360.00 fourth level. Third level students (Third Level Students High 80-100) in the University of Aden ranges between 5000 with (76\%) and 8000 with only $(25 \%)$ with only words with a mean score of (51\%) which is about half of the students (Third Level Students High 80-100) are within the range of 8000 words size while it is 7100 in the Thai university students. This low size of vocabulary size can be attributed to the weakness of secondary school education, curriculum and number of lectures in every semester. Additionally, subjects taught in Arabic (university prerequisite courses such as Islamic Culture, computer, Arabic Language, Psychology, fundamentals of Education, Psychological Health and History of Education) constitute about 25\% of English courses.

Table 4.2 Third Level Students Medium 70-79.99

\begin{tabular}{|c|c|c|c|c|c|c|c|c|c|c|}
\hline \multicolumn{11}{|c|}{ Mean } \\
\hline $\begin{array}{c}5 \\
0 \\
0 \\
0\end{array}$ & 害志 & & 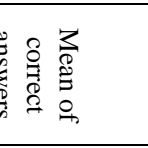 & & d & 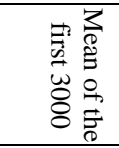 & 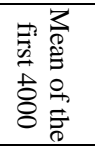 & 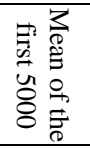 & 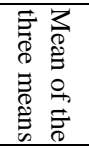 & 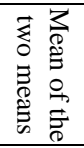 \\
\hline K1 & 10 & 9 & & $90 \%$ & & $80 \%$ & & \multirow{3}{*}{$68 \%$} & \multirow{4}{*}{$59 \%$} & \multirow{14}{*}{$40 \%$} \\
\hline K2 & 10 & & 8.7 & & $87 \%$ & & $65 \%$ & & & \\
\hline $\mathrm{K} 3$ & 10 & & 6.3 & & $63 \%$ & & & & & \\
\hline K4 & 10 & & 2.1 & & $21 \%$ & & & & & \\
\hline K5 & 10 & & 3.4 . & & $34 \%$ & & & & \multirow{4}{*}{$19 \%$} & \\
\hline K 6 & 10 & & 1.7 & & $17 \%$ & & & & & \\
\hline K 7 & 10 & & 0.6 & & $6 \%$ & & & & & \\
\hline K 8 & 10 & & 0.2 & & $2 \%$ & & & & & \\
\hline K 9 & 10 & 0.2 & & $2 \%$ & & & & & & \\
\hline K 10 & 10 & 0.1 & & $1 \%$ & & & & & & \\
\hline K 11 & 10 & 0.0 & & $0 \%$ & & & & & & \\
\hline K 12 & 10 & 0.0 & & $0 \%$ & & & & & & \\
\hline K 13 & 10 & 0.0 & & $0 \%$ & & & & & & \\
\hline K 14 & 10 & 0.0 & & $0 \%$ & & & & & & \\
\hline Total & 1 mean & 0.311111 & & $23 \%$ & & & & & & \\
\hline
\end{tabular}

Table 4.3 The Main Findings in the Three Categories

\begin{tabular}{|c|c|c|c|c|}
\hline Vocabulary size Range & 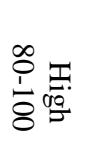 & 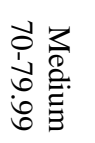 & 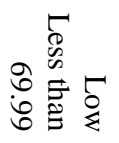 & Total \\
\hline $1000-3000$ & $80 \%$ & $80 \%$ & $50 \%$ & $70 \%$ \\
\hline $1000-5000$ & $76 \%$ & $59 \%$ & $41 \%$ & $59 \%$ \\
\hline $1000-8000$ & $51 \%$ & $40 \%$ & $21 \%$ & $37 \%$ \\
\hline
\end{tabular}


Table 4.3 clearly shows that the third Level Students (Medium 70-79.99) vocabulary size ranges between 5000 to 7000 words. The students' highest mean score correct answers are 80\% in the $\mathrm{k} 3(3000$ words), and the percentage decreases gradually to reach $65 \%$ and $68 \%$ in the $\mathrm{k} 4$ and $\mathrm{k} 5$. The mean score of the three levels is (59\%). It means that only $59 \%$ of the vocabulary size is between $1000(\mathrm{k} 1)$ and 5000 words (k 5). The mean score of the levels $\mathrm{k} 6, \mathrm{k}$ 7 and $\mathrm{k} 8$ is only $40 \%$. This result means that only about half of the students (59\%) (Medium 70-79.99) are within the range $1000=5000$ vocabulary size. The table also shows that the mean score of the third Level Students (Medium 70-79.99) in the vocabulary size levels k 1 (1000)-k 8 (8000) is only (40\%). The vocabulary size of the University of Aden students decreases from $(51 \%)$ in the (Third Level Students High 80-100) to (40\%) in the third Level Students (Medium 70-79.99).

Table 4.4 Third Level Students Low Less than 69.99

\begin{tabular}{|c|c|c|c|c|c|c|c|c|}
\hline \multirow[b]{2}{*}{ 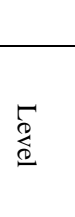 } & \multirow[b]{2}{*}{ 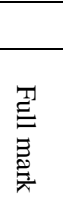 } & \multirow[b]{2}{*}{ 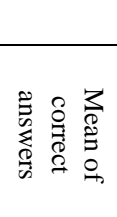 } & \multirow[b]{2}{*}{$a^{9}$} & \multicolumn{3}{|c|}{ Mean } & \multirow[b]{2}{*}{ 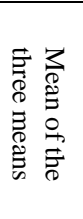 } & \multirow{2}{*}{ 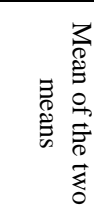 } \\
\hline & & & & 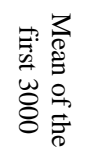 & 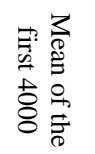 & 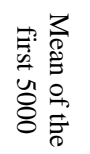 & & \\
\hline K 1 & 10 & 5.7 & $57 \%$ & \multirow{14}{*}{$50 \%$} & & & & \multirow{14}{*}{$21 \%$} \\
\hline K 2 & 10 & 5.1 & $51 \%$ & & $41 \%$ & & & \\
\hline K 3 & 10 & 4.3 & $43 \%$ & & & $52 \%$ & $41 \%$ & \\
\hline K 4 & 10 & 1.1. & $11 \%$ & & & & & \\
\hline K 5 & 10 & 0.0 & $0 \%$ & & & & & \\
\hline K 6 & 10 & 0.0 & $0 \%$ & & & & & \\
\hline K 7 & 10 & 0.0 & $0 \%$ & & & & $0 \%$ & \\
\hline K 8 & 10 & 0.0 & $0 \%$ & & & & & \\
\hline K 9 & 10 & 0.0 & $0 \%$ & & & & & \\
\hline K 10 & 10 & 0.0 & $0 \%$ & & & & & \\
\hline K 11 & 10 & 0.0 & $0 \%$ & & & & & \\
\hline K 12 & 10 & 0.0 & $0 \%$ & & & & & \\
\hline K 13 & 10 & 0.0 & $0 \%$ & & & & & \\
\hline K 14 & 10 & 0.0 & $0 \%$ & & & & & \\
\hline
\end{tabular}

Table 4.4 demonstrates that third Level Students (Low Less than 69.99) vocabulary size only ranges between $\mathrm{k} 1$ (1000) and $\mathrm{k} 3$ (3000) with low percentages ranges between $57 \%$ to $11 \%$. The mean score of the three levels $\mathrm{k} 1, \mathrm{k} 2$ and $\mathrm{k} 3$ together is only $50 \%$, and the percentages decrease to $32 \%$ when going to $\mathrm{k} 4$. The mean score of the 5000-word size is $41 \%$. The mean score of the 8000 -word size is only $21 \%$. According to this result, only $41 \%$ of the thirdlevel students (Low Less than 69.99) vocabulary size is within the $\mathrm{k} 3$ (3000).

\section{Conclusion}

Based on the students' performance in the Nation \& Beglar's (2007) Vocabulary Size Test (VST), English language third level students in the University of Aden have different vocabulary sizes. I was ranging between 1000 and 5000 words with various percentages. The high (80-100) category had different vocabulary ranges; $76 \%$ had a range of 1000 and 8000 , whereas half of the students $(51 \%)$ had a range between 1000 and 8000 . Of the $59 \%$ of students in the Medium category (70-79.99), 40\% possessed a vocabulary range between 1000 and 5000, while only $40 \%$ had a range of 1000 and 8000 . Students in the Low category (less than 69.99) were recorded with $21 \%$ having a range of $1000-8000,41 \%$ with a range of 1000-5000, and 50\% with a range of 1000-3000. Considering the total word size of the three categories together, the study found that $70 \%$ are in the 1000 3000 vocabulary range, while a little over half of them $(59 \%)$ are in the range of 1000-5000, and only $37 \%$ are in the range $1000-8000$.

With a significant majority of students, who were in their third year in the University of Aden, possessing between 1000 and 3000 vocabulary range, this study recommends the following strategies to address such a large number of Low vocabulary sized students studying English. The strategies include adjusting homework assignments for students that will lead them to do more research and more reading. 
The improvement of English courses in the university, the re-evaluation of the running courses in the departments of English at the University of Aden to update the teaching materials with daily life words referring to famous corpora such as the British National Corpus BNC and Corpus of Contemporary American English COCA, the addition of supplemental or differentiated activities, as well as the involvement of vocabulary researchers and experts in updating and designing courses.

\section{References}

Alfatle, A. B. M. (2016). Investigating the growth of vocabulary size and depth of word knowledge in Iraqi foreign language learners of English. MSU Graduate Thesis 2230. http://bearworks.missouristate.edu/thesis/2230.

Anderson, C. R., \& Freebody, P. (1981). Vocabulary knowledge. In J. T. Guthrie (Ed.), Comprehension and teaching: Research reviews (pp. 77-117). Newark, DE: International Reading Association.

Barclay, S., \& Schmitt, N. (2019). Current perspectives on vocabulary teaching and learning. Second Handbook of English Language Teaching, 799-819.

Beglar, D. (2010). A Rasch-based validation of the Vocabulary Size Test. Language Testing, 27(1), 101-118.

Biemiller, Andrew \& Catherine Boote (2006). A practical method for building vocabulary in primary grades. Journal of Educational Psychology, 98(1), 44-62.

Bornstein, M. H., \& Haynes, O. M. (1998). Vocabulary competence in early childhood: Measurement, latent construct, and predictive validity. Child development, 69(3), 654-671.

Elmasry, H. I. (2012). Depth and Breadth of Vocabulary Knowledge: Assessing their Roles in Reading Comprehension of High-School EFL Learners in the UAE (Doctoral dissertation, The British University in Dubai (BUiD)).

Eyckmans, J. (2004). Measuring receptive vocabulary size: Reliability and validity of the yes/no vocabulary. The Netherlands: LOT.

Frederiksen, J.R. (1982). A componential theory of reading skills and their interactions. Bolt Beranek and Newman INC Cambridge Ma.

Grabe, W. (1991). Current developments in second language reading research. TESOL quarterly, 25(3), 375-406.
Gyllstad, H. (2012). Validating the Vocabulary Size Test. A classical test theory approach. Poster presented at The Ninth Annual Conference of EALTA, Innsbruck, Austria, 31 May - 3 June. Retrieved

from: http://www.ealta.eu.org/conference/2012/posters/ Gyllstad.pdf.

Gyllstad, H., Vilkaite, L. \& Schmitt, N. (2015). Assessing vocabulary size through multiplechoice formats: Issues with guessing and sampling rates. ITL International Journal of Applied Linguistics, 166, 276-303.

Hazenberg, S., \& Hulstun, J. H. (1996). Defining a minimal receptive second-language vocabulary for non-native university students: An empirical investigation. Applied Linguistics, 17(2), 145-163.

Hue, H. C., \& Nation, P. (2000). Unknown word density and reading comprehension. Reading in Foreign Language, 13(1), 403-430.

Laufer, B. (1992). How much lexis is necessary for reading comprehension?. In Vocabulary and applied linguistics (pp. 126-132). Palgrave Macmillan, London.

Laufer, B., \& Nation, P. (1999). A vocabulary-size test of controlled productive ability. Language testing, 16(1), 33-51.

Lewis, M. (1993). The lexical approach. Hove: LTP.

Meara, P. (1996) The dimensions of Lexical Competence. In G. Brown, K. Malmkjaer and J. Williams (eds.) Performance and Competence in Second Language Acquisition (pp. 35-53). Cambridge: Cambridge University Press.

Nation, I. S. P. \& Beglar, D. (2007). A vocabulary size test, The Language Teacher, 31(7), pp. 9-13.

Nation, I. S. P. (1990). Teaching and learning vocabulary. New York: Heinle and Heinle.

Nation, I. S. P. (2006). How large a vocabulary is needed for reading and listening? Canadian Modern Language Review, v63 n1 p59-82.

Nation, I.S.P. (1993). Vocabulary size, growth, and use. In Schreuder, R. \& Weltens, B. (eds.) The Bilingual Lexicon. (6), 115-134. Amsterdam: Benjamins.

Nation, P. (2001). Learning vocabulary in another language. Cambridge: Cambridge University Press.

Nieuwborg, E. (1992). Tekstdekking en tekstbegrip: Een experimenteel onderzoek. Text coverage and reading comprehension: An experimental investigation $\}$ in A Halbo (Ed.) Evaluation and 
Language Teaching Liber Amicorum Frans van Passel. Bern: Peter Lang.

Ouellette, G. P. (2006). What's meaning got to do with it: The role of vocabulary in word reading and reading comprehension. Journal of educational psychology, 98(3), 554.

Schmitt, N. (1994). Vocabulary testing: questions for test development with six examples of tests of vocabulary size and depth. Thai TESOL bulletin, 6(2), 9-16.

Schmitt, N. (2000). Vocabulary in language teaching. Cambridge: CUP.

Schonell, F. J., Meddleton, I. G., \& Shaw, B. A. (1956). A study of the oral vocabulary of adults. Brisbane, Australia: University of Queensland Press.

Sciarone, A.G. (1979) Woordjes Leren in het Vreemde-talenonderwijs. Muiderberg. Netherlands: Coutinho.

Snow, C. E., Tabors, P. O., Nicholson, P. A., \& Kurland, B. F. (1995). SHELL: Oral language and early literacy skills in kindergarten and firstgrade children. Journal of Research in Childhood education, 10(1), 37-48.

Sungprakul, S. (2016). Measuring vocabulary size of Thai university students. International Journal of Social Science and Humanities Research, 4(4), 608-624.

Wilkins, D. (1972). Linguistics in language teaching. London: Edward Arnold.

Wong, W., \& Van Patten, B. (2003). The evidence is IN: Drills are OUT. Foreign language annals, 36(3), 403-423. 